\title{
Congenital Absence of Flexor Pollicis Longus Tendon Without Associated Anomalies of Thumb Hypoplasia: A Case Report and Review of the Literature
}

\author{
Mustafa Erol Demirseren • Kamran Afandiyev • \\ Mustafa Durgun • Kasim Kilicarslan • \\ Mehmet Yorubulut
}

Received: 6 March 2007 / Accepted: 11 April 2007 / Published online: 19 May 2007

(C) American Association for Hand Surgery 2007

\begin{abstract}
In this paper, we report a case of a 14-year-old girl with congenital aplasia of the flexor pollicis longus tendon who had no other associated anomalies of thumb hypoplasia and no trauma history. Flexor pollicis longus tendon anomalies are rare; several types of this congenital anomaly have been reported in the literature. The diagnosis should be considered if a patient is unable to flex the interphalangeal joint of the thumb. A hypoplastic thumb or an absent interphalangeal joint crease may be a diagnostic feature in such cases. Besides physical examination, we also used direct radiography and magnetic resonance imaging to diagnose this rare congenital anomaly in our patient.
\end{abstract}

Keywords Hand · Thumb hypoplasia · Flexor pollicis longus tendon aplasia

M. E. Demirseren $(\varangle) \cdot K$. Afandiyev $\cdot$ M. Durgun

Department of Plastic, Reconstructive and Aesthetic Surgery,

Ataturk Training and Research Hospital,

Konutkent 2 Sitesi B6 Blok C Giris, No. 4, Cayyolu,

Ankara 0681, Turkey

e-mail: medemirseren@yahoo.com

K. Kilicarslan

Department of Orthopaedics,

Ataturk Training and Research Hospital,

Ankara, Turkey

M. Yorubulut

Primer Magnetic Resonance Imaging Centre,

Ankara, Turkey

\section{Introduction}

The thumb is the most important part of the hand because of its strength, which is equal to that of all the fingers [3]. For that reason, congenital anomalies of the thumb pose more serious functional and cosmetic problems than anomalies of the other digits. One of the rarest types of anomalies is the hypoplastic thumb with congenital absence of the flexor pollicis longus (FPL) tendon without hypoplasia of the thenar muscles. When we searched the literature, we realized that only seven cases of this type of anomaly have been reported to date (Table 1). Despite its rarity, the diagnosis should be kept in mind for a patient with a hypoplastic thumb who is unable to flex the interphalangeal joint. Furthermore, an absent interphalangeal joint flexor crease may be a diagnostic feature in such cases $[8,10]$. We report a case of congenital absence of the FPL tendon with only minor hypoplasia of the thumb, and we review the literature.

\section{Case Report}

A 14-year-old girl was referred to our clinic for examination of her left hand. She had been unable to flex her left thumb at the interphalangeal joint for 6 months. She was not aware of the deficit on her left thumb until she was in middle school; as she could perform her daily tasks like writing or holding objects with her dominant right hand. She mentioned that she did not have any difficulties during the daily activities. There was no history of childhood injury and no family history of congenital anomalies. On 
Table 1 List of cases with congenital absence of the FPL tendon without the associated anomalies of thumb hypoplasia reported in the literature.

\begin{tabular}{|c|c|c|c|c|c|}
\hline Case No. & Gender & Age (Year) & Diagnosis & Treatment & Reference \\
\hline 1 & $\mathrm{~F}$ & 1 & Physical examination & Tendon transfer & Miura (1977) [7] \\
\hline 2 & $\mathrm{~F}$ & 6 & Physical examination & Two-staged tendon transfer & Arminio JA (1979) [2] \\
\hline 3 & $\mathrm{~F}$ & 13 & $\begin{array}{l}\text { Physical examination, } \\
\text { electromyography }\end{array}$ & Two-staged tendon transfer & Koster (1984) [5] \\
\hline 4 & $\mathrm{~F}$ & 7 & $\begin{array}{l}\text { Physical examination, } \\
\text { electromyography }\end{array}$ & Tendon transfer & Uchida et al. (1985) [10] \\
\hline 5 & M & 5 & Physical examination & Two-staged tendon transfer & DeHaan et al. (1987) [4] \\
\hline 6 & $\mathrm{~F}$ & 11 & Physical examination & $\begin{array}{l}\text { Tendon transfer (flexor digitorum } \\
\text { superficialis to the ring finger) }\end{array}$ & Thomas and Mathivanan (1999) 8 \\
\hline 7 & M & 10 & $\begin{array}{l}\text { Ultrasonography, magnetic } \\
\text { resonance imaging }\end{array}$ & None & Alicioglu (2007) [1] \\
\hline 8 & $\mathrm{~F}$ & 14 & $\begin{array}{l}\text { Direct radiography, } \\
\text { magnetic resonance } \\
\text { imaging }\end{array}$ & None & Present case \\
\hline
\end{tabular}

physical examination, the left thumb was slightly smaller than the right one (Fig. 1). There was no active flexion at the interphalangeal joint. Passive range of motion was $45^{\circ}$. Pinch strength was examined and compared to the normal side. The interphalangeal joint was stable. Movements of the metacarpophalangeal and carpometacarpal joints were normal (Fig. 2). Thenar eminences of both hands were almost the same in size, whereas the flexion crease was

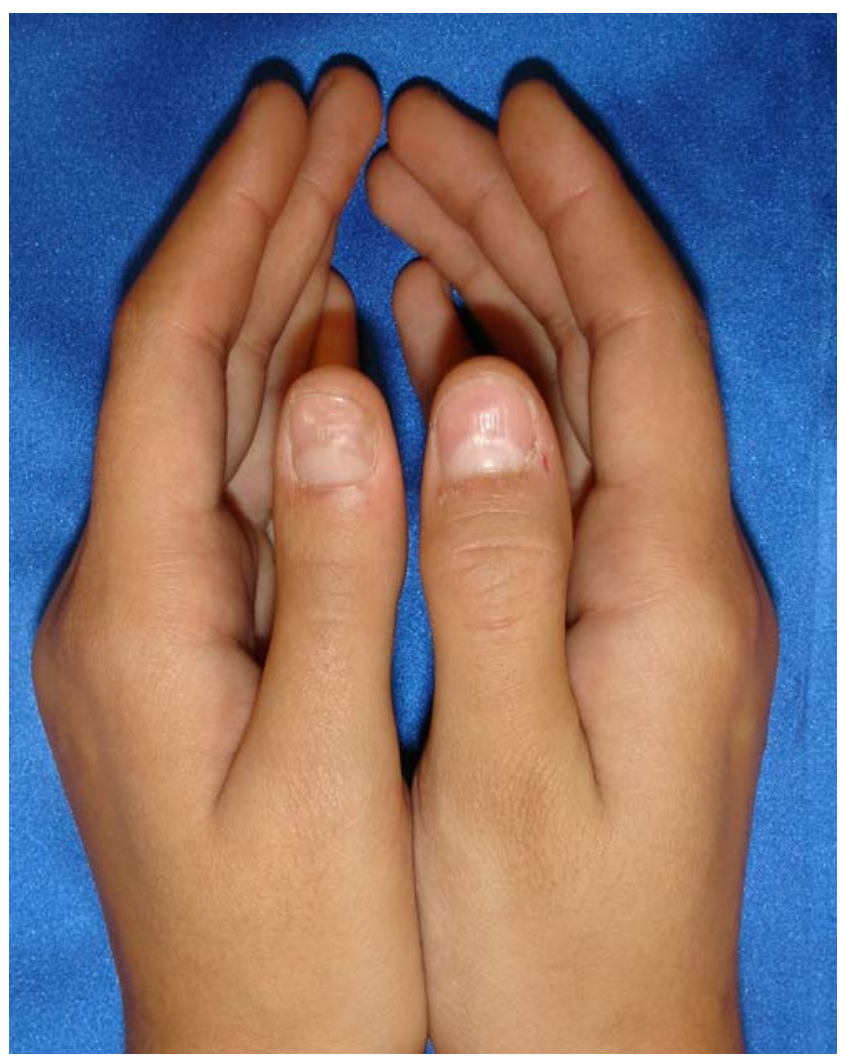

Figure 1 Dorsal view of both thumbs. Note the minor hypoplasia and less evident dorsal wrinkles at the left thumb. absent and the dorsal wrinkles were less evident at the interphalangeal joint of the left thumb (Fig. 3). Radiography showed slight skeletal hypoplasia in the patient's left thumb when compared with her right thumb (Fig. 4). Magnetic resonance imaging showed that the FPL tendon of the affected side was absent (Fig. 5). Surgical treatment was proposed but declined by the patient and her parents. There was no change in thumb flexion at the interphalangeal joint and no change in the hypoplasia after 6 months of observation.

\section{Discussion}

Thumb hypoplasia represents a spectrum of deficiencies from a slight hypoplasia to a completely absent thumb. Intermediate thumb hypoplasia and the absence of thenar muscles are occasionally associated with FPL anomalies [6]. However, a congenital anomaly of the FPL without other anomalies associated with thumb hypoplasia is rare. Despite its rarity, FPL anomaly has clinical significance in the differential diagnosis of a patient who is unable to flex the interphalangeal joint of the thumb. The congenital inability to flex the interphalangeal joint of the thumb may have one of several causes, including congenital absence of the FPL, anomalous insertion of the FPL, congenital tenovaginitis of the flexor tendon sheath, partial anterior interosseous nerve paralysis, traumatic rupture of the FPL, or anomalous connection between the FPL and the extensor pollicis longus tendons $[1,4,8,10]$. Among these, congenital absence of the FPL without hypoplasia of the thenar muscles is the rarest variation $[1,2,4,7,8,10]$.

Clinically, the affected thumb is smaller than the other with a faint or absent flexion crease and loss of active flexion at the interphalangeal joint. In addition, less evident 


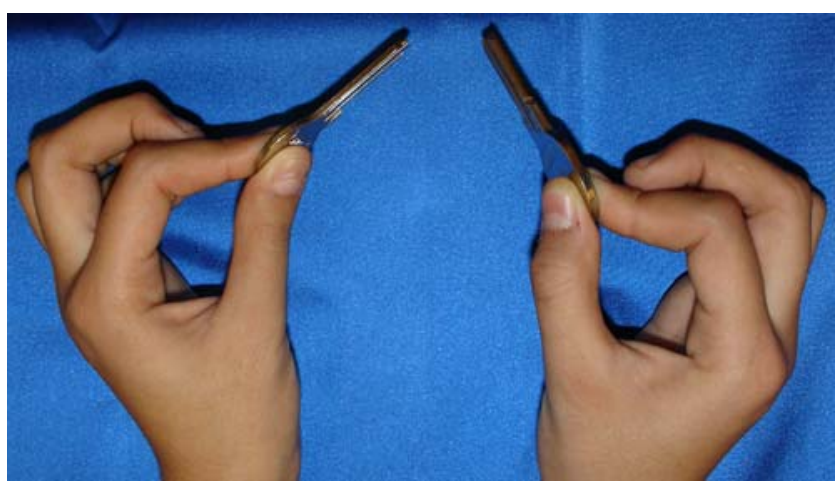

Figure 2 Movements of the metacarpophalangeal and carpometacarpal joints were normal, whereas active flexion at the interphalangeal joint of the left thumb was absent.

dorsal wrinkles caused by the loss of active flexion of the interphalangeal joint are present as in our case.

Direct radiography, ultrasonography, magnetic resonance imaging, and electromyography can be used for diagnostic examination. Although no skeletal abnormalities were observed in previously reported cases $[1,2,4,7,8,10]$, we noted slight skeletal hypoplasia in our patient's left thumb when compared with right thumb. Because magnetic resonance imaging is highly accurate and can be useful in surgical planning, we also used this complementary technique to confirm the diagnosis.

To achieve flexion of the interphalangeal joint of the thumb, the most preferred surgical technique has been tendon transfer using the flexor digitorum superficialis tendon of the ring finger in one- or two-staged operations. The achieved range of flexion after the one-staged operations $[7,8,10]$ was similar to the achieved range of flexion after the two-staged operations $[2,4,5]$ and varied between 20 $35^{\circ}$ in both groups. However, the indication of a tendon transfer in children must be evaluated carefully because a planned program of physiotherapy is not possible in infants and the results are unlikely to be satisfactory $[8,9]$. The

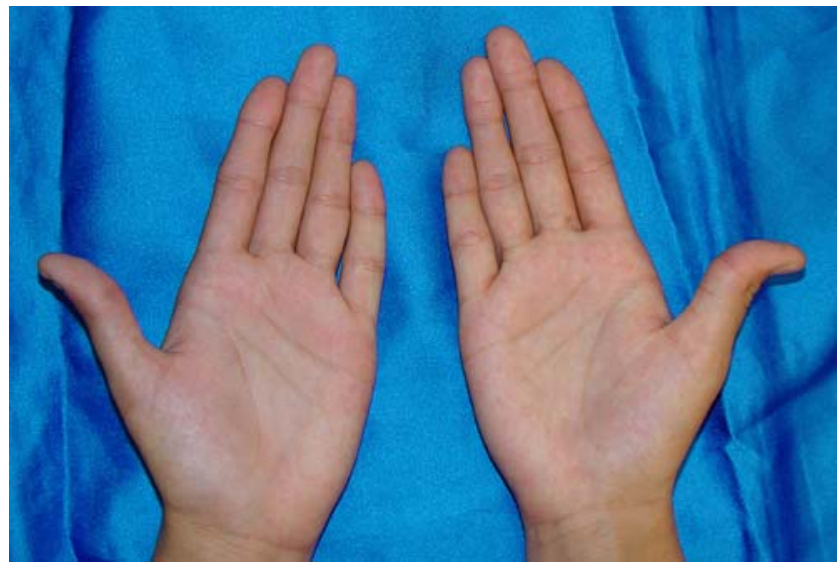

Figure 3 Flexor crease was absent at the left thumb.

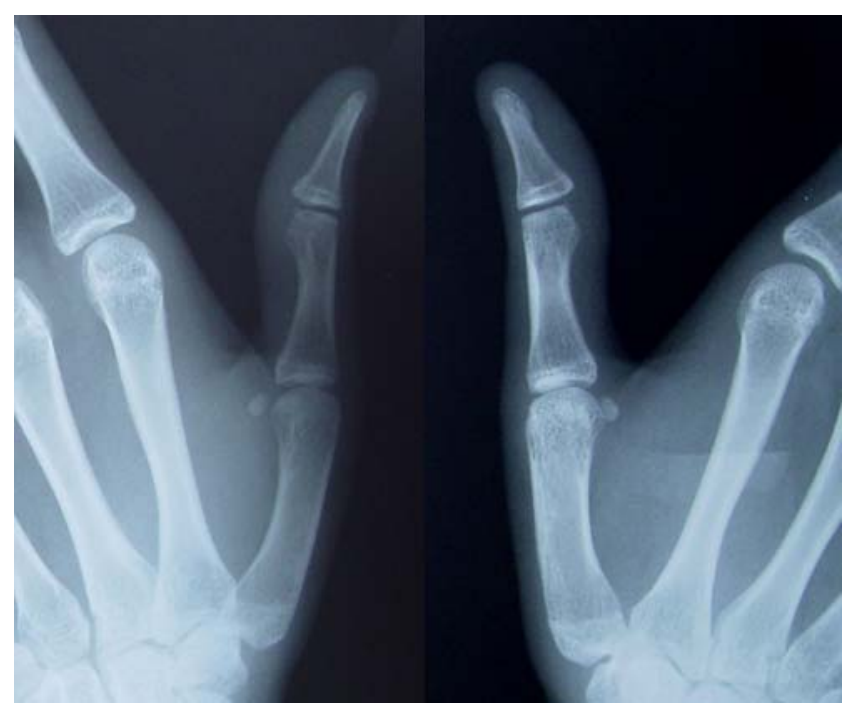

Figure 4 Radiograph shows slight skeletal hypoplasia of the left thumb.

patient and her parents did not accept the surgical treatment after they evaluated the cost-benefit in the light of our explanations because the pathology was in her nondominant hand and she had no limitations during the daily activities.

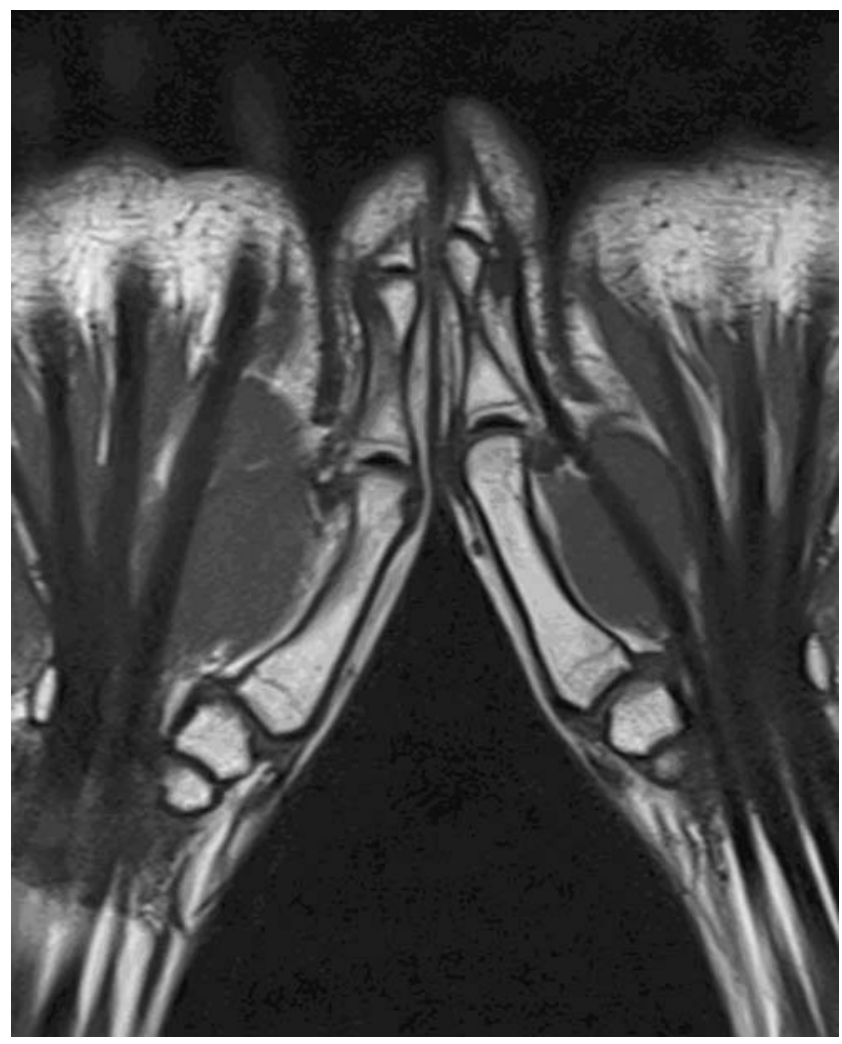

Figure 5 T1-weight coronal image of both hands shows absence of the left FPL tendon. 


\section{References}

1. Alicioglu B. Radiologic findings of the flexor pollicis longus hypoplasia. Skeletal Radiol 2007;36(1):120-3.

2. Arminio JA. Congenital anomaly of the thumb: absent flexor pollicis longus tendon. J Hand Surg 1979;4:487-8.

3. Bartlett GR, Coombs CJ, Johnstone BR. Primary shortening of the pollicized long flexor tendon in congenital pollicization. J Hand Surg 2001;26A:595-8.

4. DeHaan MR, Wong LB, Petersen DP. Congenital anomaly of the thumb: aplasia of the flexor pollicis longus. J Hand Surg 1987;12A:108-9.

5. Koster G. Isolated aplasia of the flexor pollicis longus: a case report. J Hand Surg 1984;9A:870-1.
6. Kozin SH. Deformities of the thumb. In: Green DP, editor. Green's operative hand surgery. 5th ed., vol. 2. Philadelphia: Elsevier Churchill Livingstone; 2005. p. 1445-68.

7. Miura T. Congenital absence of the flexor pollicis longus: a case report. Hand 1977;9:272

8. Thomas C, Mathivanan T. Congenital absence of flexor pollicis longus without hypoplasia of the thenar muscles. J Hand Surg 1999;24B:385-6.

9. Tsuchida Y, Kasai S, Kojima T. Congenital absence of flexor pollicis longus and flexor pollicis brevis: a case report. Hand 1976;8:294-7.

10. Uchida M, Kojima T, Sakurai N. Congenital absence of flexor pollicis longus without hypoplasia of thenar muscles. Plast Reconstr Surg 1985;75:413-6. 